\title{
Cardiac arrest from intravenous indigo carmine during laparoscopic surgery -A case report-
}

\author{
Won-Jae Lee, and Hyun-Soo Jang \\ Department of Anesthesiology and Pain Medicine, Wallace Memorial Baptist Hospital, Busan, Korea
}

Indigo carmine (sodium indigotindisulfonate) is a safe, biologically inactive blue dye routinely administered intravascularly during urologic and gynecologic procedures to localize the ureteral orifices and to identify severed ureters and fistulous communications. We report a case of hypotension, cardiac arrest, and cerebral ischemia after the administration of indigo carmine in a patient under total laparoscopic hysterectomy. (Korean J Anesthesiol 2012; 62: 87-90)

Key Words: Cardiac arrest, Cerebral ischemia, Hypotension, Indigo carmine.

Indigo carmine (sodium indigotindisulfonate) is a blue dye commonly used urologically or in gynecological surgery to observe ureteral orifices in cystocopy since its clinical introduction in 1904. Generally, it was considered pharmacologically inert, but we report a case of hypotension, cardiac arrest, and cerebral ischemia after an intravenous indigo carmine injection during a total laparoscopic hysterectomy with accompanying literature review.

\section{Case Report}

A 43 year-old female patient with American Society of Anesthesiologists (ASA) physical status I was diagnosed with uterine myoma and was scheduled to undergo total laparoscopic hysterectomy. The patient was $160 \mathrm{~cm}$ tall and weighed $63 \mathrm{~kg}$ with no unusual medical history, and in the preoperative laboratory tests, her mean corpuscular hemoglobin concentration was $7.5 \mathrm{~g} / \mathrm{dl}$.

Premedication was not used, and upon arrival in the operating room, an electrocardiogram, pulse oximeter, and non-invasive blood pressure monitor were attached. Before anesthesia, blood pressure was 150/90 $\mathrm{mmHg}$; heart rate was $90 \mathrm{beat} / \mathrm{min}$, and peripheral oxygen saturation was $100 \%$. Glycopyrrolate $(0.1 \mathrm{mg})$ and propofol $(120 \mathrm{mg})$ were IV injected, and while conducting mask ventilation with $\mathrm{O}_{2}$, rocuronium ( $5 \mathrm{~L} / \mathrm{min}, 50 \mathrm{mg}$ ) was IV injected. The patient was intubated and anesthesia was maintained with sevoflurane ( $1-2$ vol\%), $\mathrm{O}_{2}(2 \mathrm{~L} / \mathrm{min})$, and $\mathrm{NO}_{2}(2 \mathrm{~L} / \mathrm{min})$. Breathing was controlled to a tidal volume of $600 \mathrm{ml}$ and the breathing rate was $10 / \mathrm{min}$. $\mathrm{CO}_{2}$ was inserted into the abdominal cavity until the intra-

Received: April 26, 2011. Revised: 1st, May 18, 2011; 2nd, May 31, 2011. Accepted: June 1, 2011.

Corresponding author: Hyun-Soo Jang, M.D., Department of Anesthesiology and Pain Medicine, Wallace Memorial Baptist Hospital, Namsandong, Geumjeong-gu, Busan 609-728, Korea. Tel: 82-51-580-1537, Fax: 82-51-583-7114, E-mail: janghs@wmbh.co.kr () This is an open-access article distributed under the terms of the Creative Commons Attribution Non-Commercial License (http:// creativecommons.org/licenses/by-nc/3.0/), which permits unrestricted non-commercial use, distribution, and reproduction in any medium, provided the original work is properly cited. 
abdominal pressure became $13 \mathrm{mmHg}$ and the hysterectomy was done. Two units of concentrated red blood cells were transfused and there were no abnormalities with blood pressure at $120 / 80 \mathrm{mmHg}$, heart rate at 10 beats/min, and $99 \%$ peripheral oxygen saturation.

Two hours after inducing anesthesia, $5 \mathrm{ml}$ of indigo carmine was slowly IV injected to identify the ureter. One minute later the $\mathrm{E}_{\mathrm{T}} \mathrm{CO}_{2}$ fell from $33 \mathrm{mmHg}$ to $12 \mathrm{mmHg}$; blood pressure became 60/40 mmHg; peripheral oxygen saturation fell to $89 \%$, and patient displayed bradycardia and then asystole on the ECG. Inhalation anesthesia was immediately stopped and normal saline with $100 \% \mathrm{O}_{2}$ was administered. One milligram of epinephrine was IV injected; chest compressions were given, and the right radial artery was punctured and a catheter inserted to continually monitor the arterial pressure. The pulse recovered, but the patient's state did not improve so $1 \mathrm{mg}$ of epinephrine was administered 3 more times over 20 minutes. A pH of 7.095 was measured by the arterial blood gas analysis so $60 \mathrm{ml}$ of $8.4 \%$ sodium bicarbonate was IV injected (Table 1). Twenty minutes after cardiac arrest, blood pressure was $65 / 50$ mmHg; peripheral oxygen saturation was $72 \%$; $\mathrm{E}_{\mathrm{T}} \mathrm{CO}_{2}$ was 18 $\mathrm{mmHg}$, and dopamine was infused at $20 \mu \mathrm{g} / \mathrm{kg} / \mathrm{min}$ to maintain blood pressure. Atropine ( $0.5 \mathrm{mg}$ ), epinephrine ( $1 \mathrm{mg}$ ) was injected, and $20 \mathrm{ml}$ of $8.4 \%$ sodium bicarbonate was injected because a $\mathrm{pH}$ of 7.204 was measured by the arterial blood gas analysis. Forty minutes after cardiac arrest, the patient's status improved with a blood pressure of $70 / 40 \mathrm{mmHg}$, peripheral oxygen saturation of $100 \%$, and $\mathrm{E}_{\mathrm{T}} \mathrm{CO}_{2}$ of $38 \mathrm{mmHg}$, and spontaneous breathing commenced. The patient's vital signs normalized so the surgery was completed; muscle relaxation was reversed with intravenous injection of glycopyrrolate ( $0.4 \mathrm{mg}$ ) and pyridostigmine (10 $\mathrm{mg})$, and the patient was transferred to the intensive care unit with intubation. In the ICU, the blood pressure was $90 / 50 \mathrm{mmHg}$; heart rate was 100 beats/ min; $\mathrm{O}_{2}(5 \mathrm{~L} / \mathrm{min})$ was administered through the endotracheal tube, and mental status was not restored. There were no abnormalities in the brain CT, but in the brain MRI taken on the second postoperative day, there were bilateral infarctions in the subcortical white matter in the parieto-occipital lobe (Fig. 1). On the third postoperative day, the peripheral oxygen saturation did not rise more than $88 \%$ even though $\mathrm{O}_{2}$ was administered at $10 \mathrm{~L} / \mathrm{min}$ so controlled mandatory ventilation was done. On the seventh postoperative day, mechanical ventilation was stopped. Twenty days after surgery, the patient was extubated, and on the twenty-fifth postoperative day, the patient's mental status recovered, but there was motor weakness in the left arm and visual disturbance with difficulty in the lateral gaze. Three months after surgery, the patient recovered from motor weakness and visual disturbance. The patient is currently hospitalized for rehabilitation.

Table 1. Serial Arterial Blood Gas Analysis and Biochemical Data of Patient

\begin{tabular}{|c|c|c|c|c|c|c|}
\hline & Reference & OP1 & OP2 & OP3 & POD2 & POD10 \\
\hline $\mathrm{pH}$ & $7.35-7.45$ & 7.095 & 7.204 & 7.346 & 7.477 & 7.398 \\
\hline $\mathrm{PaCO}_{2}$ & $35-45 \mathrm{mmHg}$ & 53.7 & 73.7 & 37.9 & 32.2 & 39.0 \\
\hline $\mathrm{PaO}_{2}$ & $74-108 \mathrm{mmHg}$ & 182.2 & 104.6 & 86.8 & 218.0 & 215.1 \\
\hline Bicarbonate & $22-26 \mathrm{mmol} / \mathrm{L}$ & 14.2 & 23.5 & 20.36 & 24.6 & 23.4 \\
\hline $\mathrm{K}$ & $3.5-5.5 \mathrm{mmol} / \mathrm{L}$ & & 3.9 & & 3.5 & \\
\hline $\mathrm{Ca}$ & $8.4-0.2 \mathrm{mmol} / \mathrm{L}$ & & 6.7 & & 8.8 & \\
\hline
\end{tabular}

OP1: 10 minute after cardiac arrest, OP2: 20 minute after cardiac arrest, OP3: 120 minute after cardiac arrest, POD: postoperative day, $\mathrm{K}$ : potassium, Ca: calcium.
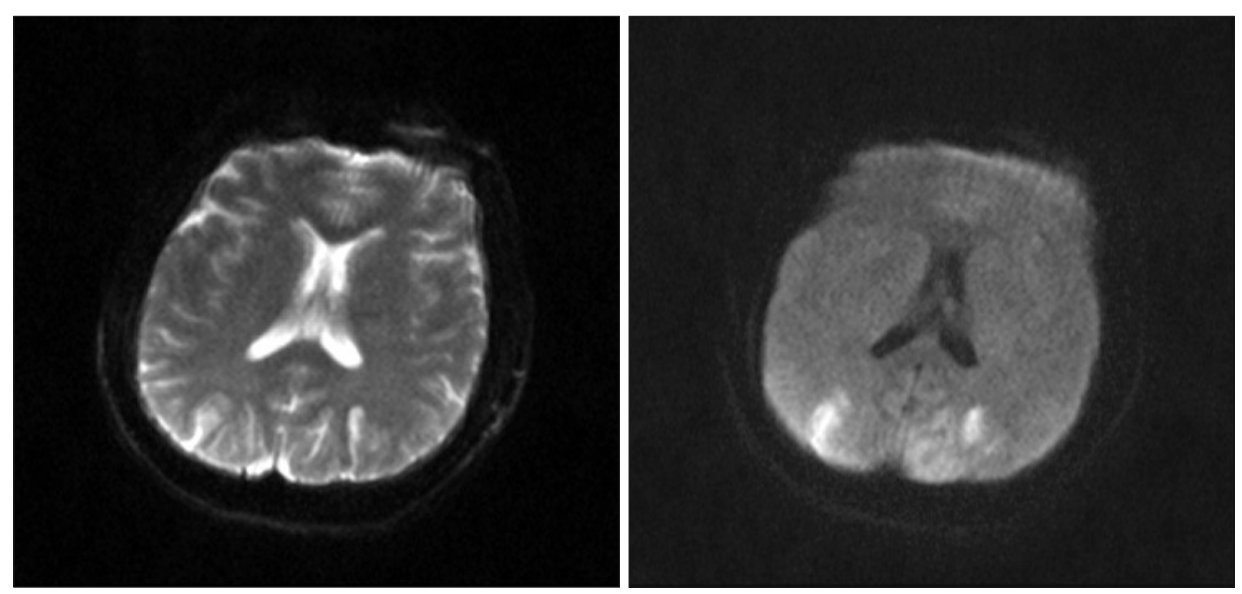

Fig. 1. Magnetic resonance imaging shows diffusion restriction of subcortical white matter in the both occipital and frontoparietal lobes. 


\section{Discussion}

Indigo carmine has been used widely and safely for IV injection, but there are rare cases of complications reported. Arterial pressure can rise from an increase in peripheral vascular resistance while bradycardia may be a reflex response from circulatory baroreceptors, and cardiac output can decrease [1]. Decreased cardiac output occurs due to increased afterload and reflex bradycardia. An increase in the mean arterial pressure and total peripheral resistance and a decrease in the cardiac output and cardiac rate with essentially no change in the stroke volume are a typical response to alpha receptor stimulation [2]. The molecular structure of indigo carmine resembles two molecules of serotonin arranged as if one is a mirror image of the other (Fig. 2 and 3). This similarity in structure suggests a cardiovascular effect [1]. Increase in blood pressure and tachycardia that arises from such similarity with the serotonin structure has been reported, but it is very rare to cause severe hypotension and cerebral infarction as in our case.

There is a case report of severe hypotension after intravenous indigo carmine in a patient undergoing radical prostatectomy under epidural anesthesia [3]. Indigo carmine has both the effects of a stimulant and a depressant; however, in that case, the commonly observed effect as a stimulant was prevented by the epidural anesthesia thus, leaving the depressant component of the drug unmasked and causing a decline in blood pressure [4]. However, in our case, epidural anesthesia was not done so this hypothesis does not explain what happened. In addition, hypotension induced by sympathectomy can be excluded. Hypovolemia, which is commonly considered as a cause for hypotension, can also be excluded because there was no heavy blood loss, and the patient's fluids were adequately replaced. Reaction to transfused blood was also considered, but the accuracy of the cross-matching was verified, and the clinical signs of mismatched transfusion such as fever, increased heart rate, and renal failure were not evident. In addition, since the temporal relationship between the time of induction and the onset of hypotension did not correspond with each other, it suggests that the probability of this factor is low. Other than these, neuromuscular blocking agents such as atracurium can cause the release of histamine and secondary vasodilation or hypotension in poorly controlled diabetes mellitus but does not

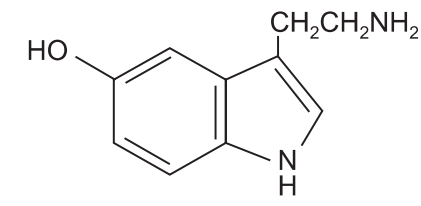

Fig. 2. The structural formula of serotonin. apply in our case. In our case, it is assumed that the insertion of indigo carmine and hypotension are clearly related because there were no other factors to cause hypotension and because the blood pressure dropped abruptly within 1 minute of injection.

In a case where severe hypotension, bronchospasm, and urticaria occurred from intravenous indigo carmine, an anaphylactic reaction with resultant hemodynamic collapse was seen to be the cause of hypotension but given her lack of prior allergies or atopy, or prior exposure to indigo carmine, it is unlikely that the patient had a true, immunoglobulin E-mediated anaphylactic reaction [5]. Therefore, it was assumed that the patient had an idiosyncratic reaction or anaphylactoid reaction to the dye; in other words, a nonimmunological reaction, possibly by means of histamine release or other mediators [6]. A domestic case report also considered idiosyncratic anaphylactoid reaction as the cause for blood pressure decline where hypotension occurred without concurrent anaphylactic signs such as cutaneous erythema, rash, laryngeal edema, or bronchospasm [7]. Coronary vasospasm has previously been associated with allergic anaphylactoid reactions and may be a possible explanation for the reversible myocardial dysfunction that developed [8]. The sodium bicarbonate administered for the correction of acidemia can temporarily increase the $\mathrm{pH}$ but can have an ill-effect on acid-base balance and the hemodynamic state by decreasing the supply of oxygen to tissues due to an increase in $\mathrm{CO}_{2}$ in the body, an increase in hypocalcaemia and hyperosmolality, and the formation of lactate as well as left movement of the oxygen dissociation curve. Therefore, the increase in $\mathrm{E}_{\mathrm{T}} \mathrm{CO}_{2}$ and decrease in ionized calcium occurred from the administration of sodium bicarbonate when the $\mathrm{pH}$ was lower than 7.25; thus, suitable pulmonary ventilation and enhancement of the blood circulation using fluids and medication is thought to be more effective than sodium bicarbonate [9].

It is inferred that cerebral ischemia is caused by an insufficient supply of oxygen, embolism, or thrombus from hypotension; however, indigo carmine-induced hypertension has been reported to be a result of interference with the nitric oxidemediated vasodilatory mechanism and direct vasoconstriction

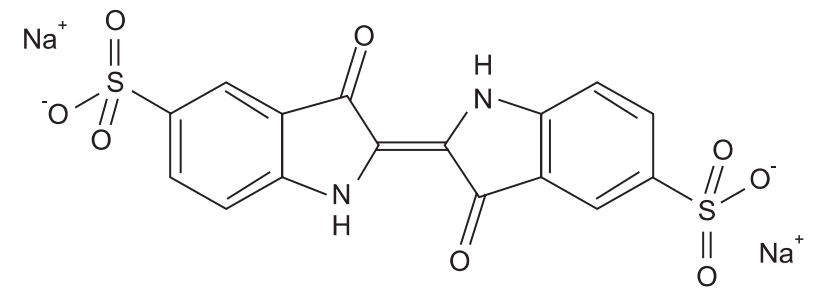

Fig. 3. The structural formula of indigo carmine. 
with spasm of the cerebral arteries [10]. In addition, a gas embolism within the artery may have been formed from the absorption of $\mathrm{CO}_{2}$ into the abdominal organs from the laparoscopy or absorption of gas bubbles created from the galvanocautery during the hysteroscopy. Twenty to thirty percent of normal adults have patent foramen ovale, and through this foramen ovale, a right to left shunt can be formed to cause paradoxical embolism and this can cause embolisms in the cerebral or coronary artery [11]. In our case, there were no EKG changes upon arrival in the ICU, and the timing of the occurrence of hypotension was not in the early stages of the laparoscopy where gas embolisms frequently occur but near the end of the surgery directly after the injection of indigo carmine so the possibility is low. The visual disturbance was cortical blindness from cortical ischemia, which occurs when there are barriers in the geniculocalcarine visual pathway. This occurrence is very rare and can be critical, but the symptoms may improve [12].

In conclusion, indigo carmine is used widely and safely as an intravenous dye, but severe hypotension can occur besides the relatively common complications of increased blood pressure and brachycardia. When complications occur, careful observation of manifestations of neurological abnormalities is necessary even after the surgery is complete.

\section{References}

1. Erickson JC, Widmer BA. The vasopressor effect of indigo carmine.
Anesthesiology 1968; 29: 188-9.

2. Kennedy WF Jr, Wirjoatmadja K, Akamatsu TJ, Bonica JJ. Cardiovascular and respiratory effects of indigo carmine. J Urol 1968; 100: 775-8.

3. Shir Y, Raja SN. Indigo carmine-induced severe hypotension in patients undergoing radical prostatectomy. Anesthesiology 1993; 79: 378-81.

4. Fairley HB. Hypotension after indigo carmine. Anesthesiology 1993; 79: 1454.

5. Naitoh J, Fox BM. Severe hypotension, bronchospasm and urticaria from intravenous indigo carmine. Urology 1994; 44: 271-2.

6. Nguyen AC, Kost E, Framstad M. Indigo carmine-induced severe hypotension. Anesth Analg 1998; 87: 1194-5.

7. Choe MH, Kim DC, Han YJ. Extreme hypotension followed by an intravenous indigo carmine injection during a radical prostatectomy. Korean J Anesthesiol 2002; 43: 389-91.

8. Ghannem M, Marsepoil T, Godard S, Ho P, Monthéli JM, Lainée R. Anaphylactic reaction with coronary spasm following coronarography. Ann Cardiol Angeiol (Paris) 1993; 42: 416-8.

9. Lee SY, Choi YK, Kim YJ, Park JW, Shin CM, Park JY. Changes in arterial and mixed carbon dioxide tension and hemodynamic states after sodium bicarbonate during hemorrhagic shock. Korean J Anesthesiol 1994; 27: 1425-32.

10. Kawaguchi Y, Hashimoto H, Kitayama M, Hirota K. Intravenous indigo carmine might cause cerebral ischemia. Acta Anaesthesiol Scand 2007; 51: 776-7.

11. Hong JG, Lee CS, Kim WT. Gas embolism during diagnostic laparoscopy combined with hysteroscopic procedure. Korean J Anesthesiol 1996; 31: 530-3.

12. Ahn KR, Choi JK, Kim CS, Kang KS, Kim JE, Yoo SH, et al. Bilateral cortical blindness due to parieto-occipital infarction after general anesthesia. Korean J Anesthesiol 2004; 47: 122-5. 